\title{
Considerações sôbre normas de conduta propostas para funcionários públicos de Israel
}

\section{HARRY KANTOR}

O presente artigo foi publicado pelo Boletim da E.S.A.P.A.C. (Escola Superior de Administração Pública da América Centrall, n? 3, vol. IV, de 15-9-59. Interessado em sua divulgação em nossa lingua, dirigitt-se o Instituto Brasileiro de Ciências Administrativas àquela entidade, pedindo the permissão para a respectiva tradução e publicação nesta Revista. Com extrema gentileza, atendeu a E.S.A.P.A.C. à solicitação e enviou ainda, ao I.B.C.A. o original inglês, de orde havia sido efetuada a tradução para o espanhol. A presente tradusão foi, assim, feita diretamente do original, sob o patrocinio do I.B.C.A.

A queda dos Perons, dos Pérez Jiménez, dos Odrias e dos Rojas Pinillas fêz com que a América Latina inaug:ırasse um novo período em sua história, de governos constitucionais e estáveis. Surgiu um novo ambiente e verificaram se, em tôdas as partes dessa região, esforços consideráveis para superar os maus hábitos do passado e dar impulso a instituições necessárias a paises progressistas. $\AA$ medida que se estimula a educação, se consttoem estradas, se expande a indústria e são melhorados os padrões de vida, torna-se óbvio que o mecanismo administrativo dêsses paises deve passar por completa revisão e reorganização.

Já muito se tem feito em diversos países para melhorar a máquina administrativa. Criaram-se escolas de administração, pôs-se em prática o treinamento em serviço, e a êsses esforços juntaram-se os programas de assistência técnica das Nações Unidas e dos Estados Unidos, para o aperfeiçoamento da administração pública. Não obstante, resta ainda muito a fazer.

A opinião pública da América Latina sem dúvida se interessaria em saber que o mesmo problema está sendo enfrentado em muitas partes do mundo. Em alguns paises, o esfôrço se dirige no sentido de impedir que os funcionários públicos se façam valer de seus cargos para enriquecimento ilícito. A Municipalidade de Nova York, por exemplo, vem de adotar um "Código de Êtica" para seus funcionários, após ter sido desco- 
berto que vários dêles se utilizavam de suas posições para obter benefícios financeiros indevidos. Noutros lugares o objetivo é afastar o funcionalismo público da política partidária.

Israel, pequeno pais, vem de receber o relatório de uma comissão criada para formular os "Princípios e Normas de Conduta dos Funcionários Públicos". Esse relatório esboça a maneira pela qual se deve conduzir um funcionário público, sendo suas recomendações de alcance bastante amplo para merecerem a consideração dos formuladores de politica da América Latina. Embora êsse relatório ainda não tenha sido adotado pelo Congresso de Israel, espera-se que a maioria de suas recomendações venha converter-se em lei.

O relatório da comissão israelense recomenda a adoção das seguintes regras para orientação do funcionário público. (Omitimos a introdução, bem como alguns trechos que não nos parecem pertinentes). (1)

\section{DEVERES GERAIS DO FUNCIONÁRIO PÚBLICO}

a) O funcionário público deve obediência e lealdade ao Estado de Israel $\mathrm{e}$ às suas leis.

b) Aos olhos do público o funcionário representa o órgão em que trabalho e o serviço público em geral. A fim de poder desempenhar suas funções e atingir seus propósitos o funcionário público necessita que o público lhe tenha confiança. É dever do funcionário proteger a repartição do serviço público, bem como abster-se de qualquer ato que possa desprestigiar o serviço e levantar suspeitas, mesmo infundadas, sôbre a integridade e honestidade do serviço público.

c) E' devier do funcionário público desempenhar, honesta e lealmente, tôdas as tarefas que lhe tiverem sido cometidas, observar as prescrições legais e servir ùnicamente-ao interêsse público.

d) E' dever do funcionário público conduzir-se, tanto em serviço como fora dêle, de maneira condizente com a função que desempenha, o pôsto que ocupa e a repartição em que está lotado.

e) E' dever do funcionário público tratar com cortesia e sem favoritismo iôdas as pessoas que a êle se dirigirem.

f) E' dever do funcionário público envidar todos os esforços a seu alcance, dentro do âmbito de suas funções, em benefício do serviço da repartição, melhorar os processos administrativos, aumentar a produtividade e assegurar a observância dos principios e normas que devem reger a conduta dos funcionários públicos.

g) O funcionário público deve conduzir-se respeitosa e cortezmente para com seus colegas, tanto de igual nivel hierárquico, como superiores ou subordinados.

(1) Nota do autor. 


\section{ATIVIDADES POLÍtICAS DOS FUNCIONÁRIOS PÚBLICOS}

a) O funcionário público deve abster-se de qualquer atividade politica ou pública que possa prejudicar, ou pareça prejudicar, sua capacidade de ver o interêsse público acima do interêsse partidário, ou sua capacidade de desempenhar suas funções em favoritismo.

b) Exige-se, especialmente dos funcionários públicos graduados ou que ocupem cargos de destaque, que se abstenham de qualquer atividade politica de excessiva evidência, inclusive apresentaçṍes públicas em nome de partido político, participação em comícios e passeatas politicas, bem: como participação, oral ou escrita, de debates políticos em tribunas públicas.

c) O funcionário público deve abster-se de qualquer atividade politica quando em serviço ou no local de trabalho.

d) O funcionário público não pode fazer uso de sua posição oficial para fins partidários. E' especialmente vedada qualquer tentativa para influenciar a opinião política dos que estiverem subordinados à sua autoridade, ou de pessoas com quem mantenha contato em decorrência de suas funções.

e) E' proibido ao funcionário público arrecadar fundos para partidos politicos ou para quaisquer grupos de natureza politica.

f) Ao funcionário público é vedado utilizar-se de suas relações politicas para obter promoção ou tratamento preferencial dentro do serviço. É, igualmente, proibiddo ao funcionário público demonstrar preferência ou discriminação para com outro funcionário, recomendar ou deixar de recomendárlo, ou orientar sua atitude para com o mesmo na fase da identidade ou divergência de pontos-de-vista politicos ou tendo em vista considerações de ordem partidária.

g) O funcionário público tem, como indivíduo, o direito de manifestar pùblicamente, pela palavra escrita ou oral, suas opiniōes sôbre assuntos públicos de ordem geral que não se refiram a seu trabalho, contanto que sejam observados os principios acima estipulados e dentro dos limites abaixo indicados:

18) O funcionário público deve expresar-se em estilo e forma condizentes com sua posição.

2:) O funcionário público não pode criticar de público, quer oralmente quer por escrito, a repartição ou órgão a que pertence.

3:) O funcionário do Estado não pode criticar de público, quer oralmente quer por escrito, qualquer outro órgão governamental, ou politica do govêrno, a menos que para assim proceder tenha obtido licença prévia de seus superiores.

\section{RELAÇÕES TRABALHISTAS}

a) A Nação e o Estado cometem funções importantes e dão ampla autoridade a funcionários públicos na expectativa de que os mesmos se 
conduzam de maneira condizente com a posição que ocupam. Assim como a qualquer cidadão, cabe ao funcionário público o direito de lutar pela melhoria de suas condições de trabalho, e de se organizar para tal fim, assim como também lhe é facultado o direito de lutar por outras atividades coletivas que incluem, entre outras, participação em qualquer movimento que tenda a melhorar os serviços públicos, a aumentar sua eficiência e a reforçar a tradição de responsabilidade do serviço público. Por outro lado, deve o funcionário, ao negociar condições de trabalho, evitar a utilização de quaisquer meios que sejam incompativeis com os laços especiais de lealdade e comunidade de propósito que o ligam ao Estado.

b) A Comissão recomenda às entidades públicas e às associações de funcionários públicos o estabelecimento de mecanismos mistos de mediação, para a solução de questões em que haja desacôrdo.

c) A comissão recomenda às associações de funcionários públicos a adoção de uma norma pela qual, em caso de disputa com uma entidade pública, a autoridade para decidir, em nome dos funcionários, sôbre medidas capazes de interferir no trabalho nessa repartição caiba exclusivamente a uma organização de funcionários públicos que tenha jurisdição em todo o pais.

4. RELAÇÕES SOCIAIS E COMERCIAIS DOS FUNCIONÁRIOS PÚBLICOS

a) O dever do funcionário público de desempenhar suas tarefas sem favoritismo e para o bem público exige dêle que se abstenha de situações capazes de solapar sua resistência a pressões materiais ou sociais que venham a desviá-lo de seus deveres.

b) A fim de obstar, tanto quanto possivel, que se criem situações capazes de dificultar o desempenho correto de suas tarefas, deve o funcionário público evitar quaisquer relaçóes de negócios, seja pessoalmente seja através de terceiros agindo em seu nome, com organizações que com êle tenham contato no curso de suas atividades funcionais.

c) Assim, o funcionário público deve evitar relações sociais muito chegadas com pessoas que tenham contatos freqüentes com êle em assunto de serviço, impedindo que tais relações possam influenciá-lo, ou parecer que $o$ influenciam, no desempenho de suas tarefas de funcionário público.

d) Ao funcionário público é proibido aceitar, de pessoa ou organização que com êle tenha contato no desempenho de suas funções, quer direta quer indiretamente, pessoalmente ou através de membros de sua familia, qualquer benefício ou presente, além dos que normalmente se recebem no curso de relaçốes sociais comuns.

5. APRECIAÇÃO, PELO FUNCIONÁRIO PÚBLICO, DE PRETENSÕES DE PESSOAS OU ORGANIZAÇÕES A ÊLE INTIMAMENTE LIGADAS

O funcionário público deve abster-se de apreciar pedidos ou solicitações ern matéria comercial, de negócios e outras, apresentados por pessoas ou 
organizações cujas relações com tal funcionário possam tornar-lhe difícil agir sem favoritismo ou, pelo menos, pôr em dúvida sua capacidade de fazê-lo. Incluem-se entre tais pessoas ou organizações, inter alia, membros de sua familia, organizações ou pessoas com as quais tenha trabalhado anteriormente à sua entrada para o serviço público, organizações ou pessoas com as quais tenha mantida relações comerciais ou de negócios. Quando tal pessoa ou organização se dirigir a êle, deverá encaminhá-la a outro funcionário. Quando isto não fôr possivel, o funcionário deverá informar seus superiores, por escrito, sôbre suas relações especiais com o postulante.

\section{RESTRIÇÕES AOS FUNCIONÁRIOS PÚBLICOS QUE TIVEREM DEIXADO O SERVIÇO}

a) A fim de evitar suspeitas de favoritismo, o funcionário público que deixar o serviço deverá abster-se, durante um ano a partir da data em que se tiver desligado do serviço, de aceitar qualquer emprêgo de pessoas ou organizações com as quais tenha mantido contato no curso de suas atividades funcionais, e às quais tenha concedido licenças, concessões, contratos para execução de serviços, etc., a menos que receba permissão especial da administração do órgão público em que tiver trabalhado (no caso de alto funcionário, da Comissão de Serviço Público).

b) O funcionário público que deixar o serviço deverá abster-se, durante dois anos, de representar qualquer pessoas ou organização perante a repartição onde tenha trabalhado, ou perante quaisquer outras repartições públicas com as quais tenha tido contato no curso de suas atividades funcionais. Da mesma forma, não deverá jamais representar qualquer pessoa ou organização perante a repartição em que tenha trabalhado, ou perante quaisquer outras repartições com as quais tenha mantido contato durante o desempenho de suas funções, nas matérias em que tenha intervido na qualidade de funcionário público.

\section{O SEGRÊDO COMO DEVER DO FUNCIONÁRIO PÚBLICO}

a) E' vedado ao funcionário público passar a qualquer pessoa informações que ainda não tenham sido divulgadas pùblicamente e que tenham chegado a seu conhecimento em razão de seu trabalho, a menos que isto seja necessário ao desempenho de suas funções ou que para tanto tenha sido autorizado por seus superiores. Tais informações são confidenciais e confiadas ao funcionário público para o desempenho de suas funções, e ùnicamente com esta finalidade.

b) $E^{\prime}$ proibido ao funcionário público utilizar-se, em seu benefício pessoal, de informações que tenham chegado a seu conhecimento em função de seu serviço. A fim de evitar suspeitas, os funcionários públicos deverão abster-se de participar de qualquer transação privada que envolva informações de que disponham e que possam ser de importância para tal transação. 
c) As proibições relacionadas nas letras a e $b$, acima, aplicam-se também a funcionários públicos após seu desligamento do serviço. Para que uni ex-funcionário público possa divulgar informações que não sejam do conhecimento público e que possua em virtude da função por êle anteriormente desempenhada, deve para tal obter permissão, por escrito, da administração do órgão onde tenha trabalhado.

\section{O DEVER DO FUNCIONÁRIO PÚBLICO DE NOTIFICAR SEUS SUPERIORES}

Na eventualidade de um funcionário público ter conhecimento de ato ilegal, ocorrido dentro da repartição em que trabalha, é de seu dever notificar seus superiores a respeito.

\section{OUTROS EMPREGOS DE FUNCIONÁRIOS PÚBLICOS}

a) O funcionário público deve dedicar o melhor de suas aptidões e capacidade de trabalho às funções que exerce na repartição em que serve. A menos que obtenha permissão de seus superiores, é lhe vedado desempenhar qualquer outro trabalho. Quando um funcionário público tiver obtido essa permissão, deverá, sempre que fôr solicitado, fornecer a seus superiores, para tal fim designados, pormenores completos sôbre a natureza de tal trabalho, local, vencimentos ou quaisquer outros beneficios dêle decorrentes.

b) E' proibido ao funcionário público aceitar um outro trabalho que possa prejudicar sua capacidade funcional na repartição em que exerce suas funções.

c) Ao funcionário público é proibido aceitar um outro trabalho que possa prejudicar, ou que pareça prejudicar, sua capacidade de desempenhar suas funções sem favoritismos ou de maneira condizente com a posição que ocupa. Entre outras coisas, é proibido ao funcionário público, no desempenho de suas funções adicionais, preparar dados e redigir requerimentos endereçados à repartição em que trabalha. Também se lhe proibe, no desempenho de suas atividades adicionais, representar pessoas ou organizações perante qualquer órgão público ou perante qualquer pessoa ou organização com quem tenha tido contato em razão de seu trabalho no serviço público.

d) Ao funcionário público é permitido participar de atividades públicas sem recebimento de qualquer remuneração, subordinando-se, entretanto, às restrições capituladas nas letras $b$ e $c$, acima.

e) Ao funcionário público é permitido participar de qualquer trabalho artístico, literário ou cientifico, que não seja de natureza permanente. O funcionário público que obtiver de trabalhos dessa natureza vantagens pecuniárias deverá informar de tal fato superiores seus, designados para tal fim. 


\section{A CONDUTA PESSOAL DO FUNCIONÁRIO PÚBLICO}

A fim de manter a reputação do órgão em que trabalha e a confiança do público, o funcionário público deverá conduzir-se, tanto no trabalha comc em sua vida privada, de maneira condizente com as normas da ética, da decència e da cortesia, devendo servir de exemplo no acatamento das leis e regulamentos.

O autor não recomenda a adoção de cada uma das normas acima por todos os países latino-americanos, apenas que as mesmas sejam estudadas por aquêles a quem couber a formulação de diretrizes politicas. Funcionários públicos eficientes e dedicados podem constituir um importante instrumento na realização das politicas governamentais. A ineficiência, o oportunismo e o nepotismo só tendem a prejudicar as tentativas ora empreendidas para melhorar as condições vigentes na América Latina. Se cada govêrno latino-americano puder elaborar seu próprio código de conduta para o funcionalismo público e formar um quadro de funcionários dedicados e que se pautem pelas normas do código, as vinte repúblicas terão dado um gigantesco passo à frente. 